\title{
Universalidad y Limites del lenguaje en Hans-Georg Gadamer. Otra aproximación al tacto hermenéutico
}

\author{
Universality and limits of language in Hans- \\ Georg Gadamer. Another approach to \\ hermeneutical touch
}

\author{
FRANCISCO DIEZ \\ CONICET, ANCBA, Universidad Católica Argentina, Universidad Austral
}

Recibido: 10/09/2020 Aceptado:20/05/2021

\section{RESUMEN}

El objetivo del trabajo es examinar los límites del fenómeno de la comprensión y del lenguaje en relación con las pretensiones de universalidad de la hermenéutica de Gadamer desde la perspectiva de su virtud del tacto. El tacto es «la virtud suprema del verdadero intérprete» (Gadamer $G W$ 9, 442) que sabe tratar con la infinitud del texto en los límites de situación hermenéutica. En la descripción de esta virtud aparecen rasgos del sentido perceptivo táctil que deben ser examinados. Su análisis busca aclarar los fundamentos antepredicativos de los límites y la universalidad de la hermenéutica de Gadamer.

\section{PALABRAS CLAVE}

\section{TACTO, LÍMITES, HERMENÉUTICA, FENÓMENO}

\section{ABSTRACT}

The aim of the paper is to examine the limits of the phenomenon of understanding and language in relation to the universality claims of Gadamer's hermeneutics from the perspective of his virtue of tact. Tact is «the supreme virtue of the true interpreter» (Gadamer $G W$ 9, 442) who knows how to deal with the infinity of the text within the limits of the hermeneutical situation. In the description of this virtue there appear features of the tactile perceptual sense that must 
be examined. His analysis seeks to clarify the pre-predicative foundations of the limits and universality of Gadamer's hermeneutics.

KEYWORDS

TACT, LIMITS, HERMENEUTICS, PHENOMENON

El tRABAJo TIENE COMo objetivo examinar los límites del fenómeno de la comprensión y la universalidad del fenómeno del lenguaje planteados por Gadamer en Verdad y Método, junto al esfuerzo de limitación lingüística y formulación de un deseo universal de lenguaje, propuestos como reelaboración en textos posteriores. El examen se desarrolla en perspectiva de una cuestión en apariencia marginal a estos temas, la cuestión del tacto considerado como sentido perceptivo y como virtud ético-social. Gadamer no se ocupa del tacto en su dimensión perceptiva. En cambio, en su dimensión ético-phronética lo considera nada menos que «la virtud suprema del verdadero intérprete» ${ }^{1}$ para el trabajo con los límites de la situación hermenéutica. La herencia de Helmholtz es reconocida como fundamental para esta virtud del tacto. La herencia de Herder, si bien es referida a menudo en temas centrales para la hermenéutica, pasa totalmente desapercibida a Gadamer en el acercamiento entre comprensión, lenguaje y tacto perceptivo que propone como una de sus tesis principales. ¿La causa de este silencio es que entre virtud y sentido no cabe vínculo alguno? ¿Se trata solo de un desplazamiento retórico? ¿Metafóricamente decimos de algunos hombres que «tienen tacto» dentro del ámbito ético-phronético como literalmente decimos de todos los hombres que poseen el sentido del tacto dentro del campo perceptivo-fenomenológico?

En el acercamiento de sentido y virtud con lenguaje y comprensión, el trabajo propone la existencia de un vínculo más complejo aproximándose en tres movimientos a la pregunta por la posible operatividad en Gadamer de la herencia en torno a la percepción táctil. I. Examinaremos los límites de la comprensión y su respuesta en la universalidad del lenguaje; fundamento de la pretensión filosófica de la hermenéutica. II. Analizaremos los límites lingüísticos y su respuesta en la universalidad de un deseo de lenguaje; salvaguarda tardía de la universalidad filosófica del oído. III. Frente a los límites de la comprensión, (III.1) indagaremos la herencia expresa de Helmholtz que responde al problema metodológico de estos límites en las ciencias del espíritu a partir del cual Gadamer desarrolla su virtud del tacto en Verdad y Método. Y frente a los límites del lenguaje, (III.2) intentaremos desentrañar la herencia no expresa de Herder que al enlazar el lenguaje y

1 H.-G. Gadamer, «Wer bin Ich und wer bist Du?» (1986), Gesammelte Werke 9, Tübingen: M. Siebeck, 1999, p. 442. 
la comprensión con el mencionado sentido parece hacer eficaz su dimensión perceptiva en el juego entre límites, universalidad y deseo de lenguaje.

\section{I.}

La cuestión de los límites del aparecer fenoménico es uno de los problemas metodológicos asumidos por la hermenéutica de Gadamer como base fenomenológica de Verdad y Método. Tal cuestión se asume en relación con un fenómeno que atraviesa todas las referencias humanas al mundo y del cual el fenómeno hermenéutico es una profundización: el fenómeno de la comprensión. Sus límites son evidentes pues su universalidad de predicación -todos los hombres comprenden o todas las referencias humanas al mundo son comprensivas- no se corresponde con una infinitud de alcance ni de resultados -nadie comprende todo, todo el tiempo-. Además de evidentes son diversos. Gadamer examina su multiplicidad en momentos claves de su obra mayor. En la introducción, indica la necesidad de reconocer los límites de la predominancia metodológica de las ciencias de la naturaleza y la pretensión de universalidad de su criterio de verdad. Su modelo debe ser limitado por ser limitante de toda comprensión en tanto pretende ser su paradigma. En la primera parte, refiere al reconocimiento en la experiencia del arte de una ilimitación como infinitud de sentido que debe ser protegida de toda restricción, ya que hace posible la transgresión de los límites de la realidad y es el imperativo más claro para que la conciencia científica reconozca sus límites. En la segunda parte, señala la necesidad de reconocer los límites de la comprensión histórica en tanto «todo presente finito tiene sus límites». ${ }^{2}$ Eso exige superar las limitaciones de un enfoque epistemológico del problema hermenéutico en las ciencias históricas y percibir conjuntamente los límites de la vigilancia de la conciencia histórico efectual, y con ella los de toda filosofía reflexiva. En síntesis, frente a la limitación de la comprensión que el paradigma científico produce por defecto y la infinitud del arte evidencia por exceso, en la historicidad de las situaciones particulares se reconocen los límites del fenómeno universal de la comprensión, en los que, por ser parte de nuestra insuperable finitud, estamos atrapados cuando intentamos comprender una verdad.

En la tercera y última parte de la obra, los límites de este fenómeno tienen como respuesta fundamental la universalidad de otro fenómeno, del que Gadamer hace un tratamiento puramente fenomenológico -según su propio decir-, el del lenguaje. ${ }^{3}$ El término «universalidad» es clave para mediar entre límites y comprensión. Desde la semántica, es un término utilizado en singular

2 H.-G. Gadamer, «Wahrheit und Methode», Gesammelte Werke 1, Tübingen: M. Siebeck, 1990, p. 307. En adelante $G W 1$.

3 Cf. H.-G. Gadamer, «Vorwort zur 2. Auflage» (1965), GW 2, p. 427 y GW 1, p. 446. 
para referir de una sola vez a la universalidad de la relación de lenguaje y pensamiento, entendida como unidad interna e indisoluble entre lenguaje y comprensión que da por resultado la unidad de ambos fenómenos (herencia recibida de J. G. von Herder y W. von Humboldt). Desde la lógica, se trata de un singular que hace de término mediador central en la figura silogística de la totalidad de la obra: universalidad dicha del fenómeno de la comprensión al comienzo y del fenómeno del lenguaje al final que une al segundo con el primero en tanto lo convierte a la vez en su medium y centro. El lenguaje encarna la doble figura de un horizonte que es un «espacio sin límites» o «elemento sin límites» para la orientación de la comprensión en sus fusiones y una fuerza que permite un uso ilimitado de medios limitados. ${ }^{4} \mathrm{~A}$ pesar de que las formas lingüísticas sean limitadas, tanto el enunciado como la pregunta en su apertura, ofrecen al fenómeno universal y limitado de la comprensión el centro mediador de una universalidad ilimitada para su ejercicio dialógico infinito. Así los límites de nuestra finitud al comprender parecen poder transgredirse gracias a su unidad indisoluble con la universalidad sin límites del fenómeno lingüístico.

II.

La universalidad e ilimitación del lenguaje como pretensión de transgredir el encierro insuperable de la comprensión en la finitud motivó dos críticas bien conocidas. 1) La barrera teórica de los fenómenos no-lingüísticos (nichtsprachliches) levantada por J. Habermas en los años 70 a partir de «aquellas expresiones de la vida específicamente incomprensibles» ${ }^{5}$ ante las que nos quedamos sin palabras. Fenómenos incomprensibles e inexpresables como los de fuerza y poder que cuestionan la unidad de lenguaje y comprensión, y por tanto los límites del comprender, así como su transgresión en el ejercicio infinito del diálogo. Del mismo modo, los fenómenos de violencia lingüística objetan la universalidad del lenguaje como medio y centro de entendimiento. 2) La barrera práctica de la interrupción del diálogo construida por J. Derrida en los años 80 que en el modo de un no querer entenderse en la conversación hizo frente a la buena voluntad de entendimiento y también al cumplimiento dialógico del lenguaje. Ante estas barreras-límites, Gadamer repensó la pretensión de universalidad de su hermenéutica en una serie de escritos de los años 70 a 90 dedicados a la finitud humana, ya no en los límites de la comprensión, sino

4 Cf. H.-G. Gadamer, «Die Vielfalt der Sprachen und das Verstehen der Welt» (1990), $G W$ 8, p. 345, y «Rethorik, Hermeneutik und Ideologiekritik. Metakritische Erörterungen zu 'Wahrheit und Methode'» (1967), GW 2, p. 237.

5 J. Habermas, «Der Universalitätsanspruch der Hermeneutik», Hermeneutik und Ideologiekritik, Frankfurt a M.: Suhrkamp, 1971, p. 133. 
en los límites del lenguaje. Uno de los textos que trata sistemáticamente este asunto es «Los límites del lenguaje» (1985), donde Gadamer distingue cuatro niveles correlativos: 1) la autolimitación (Selbst-einschränkung) del lenguaje, 2) los límites de lo pre-lingüístico (Vorsprachliche), 3) los límites de lo que sin ser aún lenguaje está junto a él (Nebensprachliche), y 4) los límites de lo que está por encima del lenguaje (Übersprachliche).

1) En todo fenómeno de expresión escrita de nuestro pensamiento, el lenguaje se impone una auto-limitación universal. Se limita al escribirse como se olvida (Selbstvergessen) al hablarse. A esa autolimitación le es inherente un intento constante por superarla que se evidencia en el vínculo de la lectura con la universalidad del oído propuesta por Aristóteles (a la que, según Gadamer, tanto Herder como Rousseau al ocuparse del origen del lenguaje no habrían prestado suficiente atención). ${ }^{6}$ Contra la primacía de la vista en Metafísica, la preeminencia del oído en De Sensu reside en que este sentido puede oír el lenguaje en todas sus diferencias posibles. ${ }^{7}$ En la lectura de lo escrito(auto)limitado, el oído da cuenta de la «plena potencialidad» del lenguaje gracias a la cual a pesar de los límites de nuestra finitud podemos representar lingüísticamente de forma anticipada algo que no está actualmente en los límites del presente histórico. Sobre esta universalidad auditiva, retomada de Verdad y Método, la hermenéutica es propuesta como una filosofía del oír. ${ }^{8}$

2) Los límites de lo pre-lingüístico exigen para Gadamer volver no solo sobre la percepción aristotélica, sino sobre su noción de experiencia (ejemplo de cómo un ejército se detiene parafraseado también por Herder). Así como la acumulación y retención de percepciones dan por resultado la experiencia en tanto formación de lo universal, ofreciendo un comienzo sin comienzo, la formación del lenguaje se da en la convivencia límite con los fenómenos no-lingüísticos (fuerza, poder, hambre, amor) que son pre-lingüísticos porque miden el espacio dentro del cual el lenguaje puede comenzar.

3) Los límites de lo que está junto al lenguaje son la risa y el llanto. El niño que ríe y aprende una lengua se ejercita con otros, pero sin ser aún un verdadero comunicarse como juego de pregunta y respuesta. Su juego es un diálogo prelingüístico, en el cual «lo prelingüístico está siempre, en cierto

6 La crítica de Gadamer es difícil de entender por el valor que Herder le da al oído en la existencia del lenguaje. Su crítica es quizá demasiado derridiana, extrapolando las sugerencias de J. Trabant, «Herder's Discovery of the Ear», en K. Mueller Vollmer (Hg.), Herder Today, De Gruyter, 1990, pp. 345-366.

7 «Esta universalidad del oído llama la atención sobre la universalidad del lenguaje.» H.-G. Gadamer, $G W 1$, p. 351.

8 Gadamer propone una «filosofía del oír», pues «el que oye, oye con eso aún algo más, es decir, también lo invisible y todo lo que se puede pensar... porque existe el lenguaje.» H.-G. Gadamer, «Über das Hören» (1998), Hermeneutische Entwürfe, Tübingen: M. Siebeck, 2000, p. 48. 
sentido, de camino a lo lingüístico.» $\rangle^{9}$ En ese acercamiento hay una apertura ilimitada a una formación continua, por la cual la Sprachlichkeit se hace Versprachlichung.

4) Gadamer alude finalmente «a lo que está por encima de lo lingüístico, al límite más allá del cual está lo no dicho (Ungesagten) y, quizá, lo indecible (Unaussprechlichen). . ${ }^{10} \mathrm{El}$ lenguaje se realiza en la ilimitación del diálogo porque en su proceso infinito lo dicho queda indefectiblemente unido con eso que está más allá de su límite, lo no dicho y lo indecible, por eso «no hay, en el fondo, ninguna conversación que concluya realmente, pues un acuerdo real, un acuerdo total entre dos hombres contradice la esencia de la individualidad. ${ }^{11}{ }^{11}$ Los límites del lenguaje, que son también los de nuestra insuperable finitud, hacen necesaria la ilimitación de la conversación. ${ }^{12}$

La conclusión de Gadamer en este texto es que la dificultad más profunda inherente a estos límites lingüísticos es el reconocimiento de la finitud humana ante el deseo de querer decir. Cuando, encerrado en los límites de una situación y lengua particulares, un hablante está buscando la palabra correcta que alcanza al otro tiene la conciencia de que no termina de encontrarla para dar(se) a comprender. Se trata de «un deseo insatisfecho de la palabra pertinente: probablemente esto sea lo que constituye la vida y la esencia verdaderas del lenguaje.» ${ }^{13} \mathrm{El}$ deseo de querer decir que en su unidad con el pensamiento se extiende al deseo de querer comprender(se) es insatisfecho porque toca la finitud humana en los límites de lo no dicho y lo indecible en todas direcciones: con lo prelingüístico en el límite inferior, con lo sobrelingüístico en el superior, con lo cercano al lenguaje en el medio, y con su autolimitación interna en el querer decir escribiendo. Sobre la pretensión de universalidad de este deseo insatisfecho, Gadamer formulará el

9 H.-G. Gadamer, «Grenzen der Sprache» (1985), GW 8, p. 357.

10 Ibid., p. 358.

11 Ibid., p. 359.

12 Gadamer pone el ejemplo de la traducción de una lengua extranjera como experiencia del límite sobrelingüístico que exige la infinitud de conversación: «diría que es un límite que siempre puede ser excedido dando algunos pasos más y que siempre promete un mejor resultado. [...] Llevar a cabo la transformación del tacto lingüístico (Sprachgefühls) y de los contenidos lingüísticos del hablante extranjero en el tacto lingüístico y los contenidos lingüísticos de la propia lengua, es, pues, un proceso infinito. Es una conversación, siempre inacabada del traductor consigo mismo.» Ibid., p. 360. Respecto a ese tacto, es interesante lo que afirma en Verdad y Método sobre el expandirse de la percepción: «Lo que ya habíamos mostrado con el ejemplo de la traducción y con las posibilidades de entenderse más allá de los límites de la propia lengua: el mundo lingüístico propio en el que se vive no es una barrera que impide todo conocimiento del ser en sí, sino que abarca por principio todo aquello hacia lo cual puede expandirse y elevarse nuestra percepción.» H.-G. Gadamer, $G W$ 1, pp. 450-451.

13 H.-G. Gadamer, «Grenzen der Sprache» (1985), GW 8, p. 361. 
principio supremo de su hermenéutica: «nunca podemos decir enteramente lo que quisiéramos decir.» ${ }^{14}$ Limitada por el nunca completamente poder de un querer, la universalidad del lenguaje se transforma en la universalidad de un deseo insaciable de lenguaje y comprensión que es otro modo más de nuestra insuperable finitud. ${ }^{15}$

III.

Junto a la universalidad del lenguaje suscitada por los límites de la comprensión y a su reelaboración en la del querer decir suscitada por los límites del lenguaje, creo reconocer otra pretensión de universalidad, subyacente a estos problemas. Es la universalidad del tacto operante a través de una triple herencia que procede expresamente como arte y virtud de Hemholtz (III.1), tácitamente como sentido perceptivo de Herder (III.2) y como ambas de Aristóteles. ${ }^{16}$

(III.1) En la primera parte de Verdad y Método bajo el problema metodológico en las ciencias del espíritu que concreta el de la limitación de la comprensión, como hemos visto, Gadamer asume expresamente de Helmholtz la idea de un tacto artístico o psicológico como noción epistemológica reguladora que convierte en virtud ético-phronética del trato con los límites. En la primacía de las ciencias de la naturaleza sobre las del espíritu, Helmholtz considera que lo propio de las primeras es el método de inducción lógica que permite extraer reglas o leyes de la acumulación de datos empíricos a partir de ceñirse a hechos y sensaciones sin necesidad de recurrir a la memoria. ${ }^{17}$ Lo propio de las segundas es también una inducción, pero artístico-instintiva vinculada a ciertas capacidades perceptivo-psicológicas, en particular, a un tacto que regula la inducción en la mayor dependencia que estas ciencias tienen de la memoria. El tacto artístico es la disposición primera y fundamental que permite intuir semejanzas y conectar elementos y recuerdos afines sin poder dar razón de esa afinidad. Gracias a él, las diversas experiencias confluyen inductiva y reguladamente en la memoria del científico del espíritu. Ese tacto

14 H.-G. Gadamer, «Europa und die Oikoumene» (1993), GW 10, Tübingen: M. Siebeck, 1999, p. 274.

15 Por estas reelaboraciones, J. Grondin interpreta que la clave de la universalidad lingüística en Verdad y Método está en la noción de palabra interior que acerca lenguaje y Encarnación. Asumiendo una perspectiva genética en su descripción fenomenológica del lenguaje, Gadamer ya habría indicado tempranamente con ella la idealidad de esa búsqueda o deseo insatisfecho en las palabras balbuceantes que exteriorizamos.

16 La herencia aristotélica no puede ser examinada en este trabajo. Su análisis sólo será indicado a fin de esclarecer el fundamento táctil de la phrónesis gadameriana.

17 Cf. H. von Helmholtz, «Über das Verhältniss der Naturwissenchaft zur Gesammtheit der Wissenschaften», Vorträge und Reden I, Brunswick: Friedrich Vieweg, 1896, p. 167 y ss. 
es una característica personal que surge en el científico por su trato asiduo con otros al modo de un tacto social, que además encarna en el ámbito epistémico la preeminencia que el tacto como sentido perceptivo tiene para los fisiólogos de la época. ${ }^{18}$ Por el contrario, para Gadamer, el tacto no es una característica exclusiva de un individuo ni está ya desarrollada en su naturaleza. Es una capacidad histórico-comunitaria con rasgos de la sensibilidad perceptiva, pero necesitada de formación al igual que la memoria. Recordemos que, para el hermeneuta, los conceptos de formación y tacto (como los de sentido común, capacidad de juicio y gusto) en su sentido prekantiano estaban ligados a prácticas compartidas y reconocidas en el interior de cada comunidad. En qué consistía «tener tacto» podía ser identificado por referencia a sus portadores y a las costumbres de cada tradición de pertenencia. ${ }^{19}$ Kant canceló esa relación con su fundamentación trascendental de la estética y obturó el sustrato conceptual que le servía de justificación a las ciencias del espíritu. La pretensión gadameriana de recuperación semántica se apoyó en la idea herderiana de formación como ascenso a la humanidad. En concordancia con Hegel, para Herder y Gadamer los hombres devienen humanos como resultado de un proceso formativo de las capacidades comunitarias de las que están dotados en tanto seres históricos. La memoria es una de ellas. Como peculiar disposición para el olvido requiere de formación y ser ejercitada, por eso si bien está en todos, en cada uno es diferente; «esto mismo vale para

18 La inducción artística de Helmholtz tiene influencia de John Stuart Mill y su noción de tacto, del fisiólogo J. G. Steinbuch (1770-1818). Steinbuch se opone a una fisiología kantiana proponiendo que la intuición espacial (ideas de líneas, superficies y cuerpos) se ajusta a las cosas mismas y surge de una interacción entre las ideas de la voluntad y las sensaciones (motor-idea). El tacto es el sentido primero y fundamental para la percepción espacial en tanto las ideas táctiles se toman como ideas de un mundo externo: «Antes de que podamos representar los objetos de nuestro mundo externo conocido por el tacto como disponible fuera de nosotros, debemos entender, además de estos objetos, representándonos. Debemos tener conciencia de nosotros mismos, una autoconciencia debe estar presente en nuestra mente, si queremos traer a la claridad de la conciencia ese objeto exterior a nosotros.» J. G. Steinbuch, Beytrag zur Physiologie der Sinne, Nürnberg: L. Schrag, 1811, p. 106. Por el vínculo entre tacto y autoconciencia, distinguimos también nuestro propio cuerpo de otros cuerpos: "Yo soy eso mismo, que mis dedos activamente tocan. Aquí hay verdadera autoconciencia.» (p. 113). Sus ideas son discutidas por otro fisiólogo citado por Helmholtz, Johannes Müller, que también atribuye prioridad al tacto: «nosotros determinamos inmediatamente en el sentido del tacto la extensión de todos los cuerpos que se nos resisten.» J. Müller, Handbuch der Physiologie des Menschen, Coblenz: J. Hölscher, 1838, 40, 2:2, p. 269.

19 Aquí opera la cercanía entre la virtud de tener tacto y el sensus communis como una virtud de buen trato social que Gadamer retoma de Shaftesbury. En la tradición aristotélica, el tacto perceptivo se identifica con el sentido común interno por ser fundamento de la sensibilidad y ser su órgano, interior del cuerpo. 
el concepto de 'tacto' que emplea Helmholtz.» ${ }^{20}$ La formación del tacto se concreta en el doblez mediador de la circularidad hermenéutica: en el trato con lo particular de las situaciones humanas el tacto sirve de sustento a la formación del juicio y del conocimiento en las ciencias del espíritu, y al mismo tiempo presupone la formación como suelo tradicional de apertura a partir del cual él mismo resulta formado. Por esta razón para Gadamer es una capacidad histórica configurada indisociablemente por la singularidad de la formación del investigador y la del ethos comunitario al que pertenece, por lo cual no se puede aprender ni imitar. Sobre estas distinciones respecto al tacto de Helmholtz, Gadamer ensaya su propia definición sugiriendo el rasgo perceptivo de esta capacidad virtuosa histórico-comunitaria:

Bajo tacto entendemos una determinada sensibilidad y capacidad de percepción de situaciones, así como para el comportamiento dentro de ellas cuando no poseemos respecto a ellas ningún saber derivado de principios generales. En este sentido el tacto es esencialmente inexpresado e inexpresable. Puede decirse algo con tacto, pero esto significará siempre que se rodea algo con mucho tacto, que se deja algo sin decir, y 'falta de tacto' es expresar lo que puede evitarse. ${ }^{21}$

En términos generales, la definición resume el valor hermenéutico del tacto para el problema metodológico de las ciencias del espíritu al saber tratar con los límites del comprender en el momento crítico de aplicación sobre una situación particular que exige la revisión de prejuicios. En el vínculo con la singularidad limitante de cada situación, el tacto anticipa la virtud

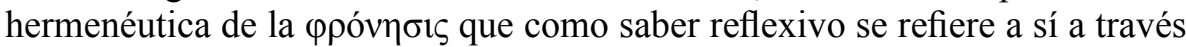
de la comprensión primera del otro en la escucha. La comprensión ( $\sigma \dot{v} v \varepsilon \sigma \iota \varsigma)$ del otro (amigo o texto) es según Gadamer inherente a la virtud del saber moral, la $\varphi \rho o ́ v \eta \sigma ı \varsigma$ que se concreta gracias a la virtud de tener tacto, lo que Aristóteles llama $\dot{\varepsilon} \pi \imath \delta \dot{\varepsilon} \xi ı s$. Con ese otro que no solo comprendemos sino sabemos tratar, estamos en relación comunitaria de pertenencia, por eso el sí atrapado en los límites de su propia situación puede ser afectado-tocado por la particularidad de la situación ajena en cuyos límites el otro debe actuar. ${ }^{22}$ En el vínculo con el decir, el tacto anticipa el carácter ético del diálogo en la

20 H.-G. Gadamer, GW 1, p. 21.

21 Ibid., p. 22.

22 En «la virtud hermenéutica (...) lo primero es entender al otro». Hans-Georg Gadamer, «Vom Wort zum Begriff», Jean Grondin (Hg.), Gadamer Lesebuch, Tübingen, M. Siebeck, 1997, p. 110. Por eso en Verdad y Método Gadamer refiere a la figura aristotélica opuesta y

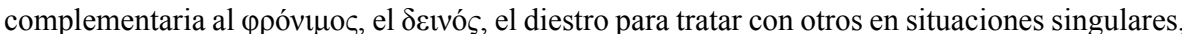
pero que no se guía por su ser moral. Sólo por esto último, se diferencia y opone a quien tiene

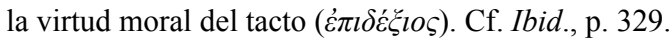


subtilitas applicandi como saber expresar que es menos un método y más un poder que requiere de una particular finura de espíritu.

Ambos vínculos generales se esclarecen en los detalles de la definición citada anteriormente. En la primera frase, la descripción literal del tacto como sentido «entendemos una determinada sensibilidad y capacidad de percepción» se aplica al campo epistemológico al recibir su determinación ético-phronética como percepción de los límites particulares de las situaciones ajenas y propias. Tal cercanía no es metafórica. ${ }^{23}$ Solo es posible enunciar tres razones de esta cercanía entre el tacto como sentido y como virtud que se remontan a la herencia aristotélica sobre el tacto. a) Su punto de apoyo es la

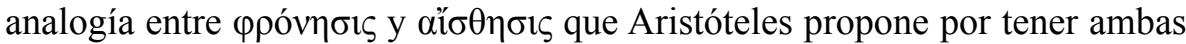

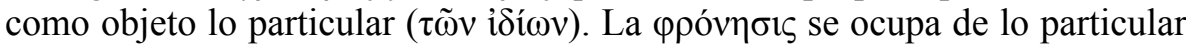
(acciones y decisiones) que es de lo que hay percepción sensible. b) La analogía se apoya en otra cercanía más profunda entre la virtud de tener tacto

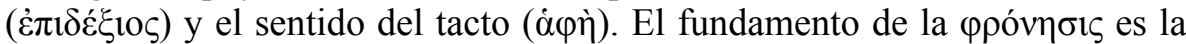
destreza moral en la virtud de tener tacto como el fundamento de la aǐ $\theta \eta \sigma ı \varsigma$ es el sentido del tacto. c) Entre ambas hay una primacía y un paralelismo que las asemeja. Primacía, porque gracias al tacto perceptivo todo viviente

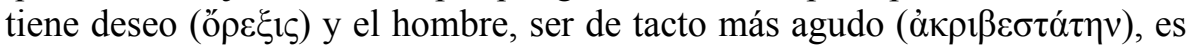

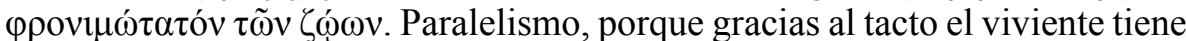
la percepción primaria del placer y dolor propios (no solo texturas, por eso el sentido es causa de intemperancia moral) y gracias a la virtud del saber moral, que es tener tacto, el amigo percibe el placer y dolor de otro, y no solo sabe de él, sino sabe tratarlo y comportarse dentro de los límites en que se encuentra. Tales cercanías confirman, a mi juicio, la proximidad que Gadamer deja establecida en su definición entre el tacto como percepción y la virtud éticophronética del amigo hermeneuta. Su sensibilidad y capacidad de percepción es necesaria en situaciones particulares porque éstas no ofrecen un principio

23 La relación entre la literalidad del tacto perceptivo (1) y la metaforicidad del tacto ético-phronético de Gadamer (2) y del tacto artístico-psicológico de Helmholtz (3) es propuesta en esos dos grados de distanciación metafórica respecto al sentido original por P. Karczmarczyk, Gadamer: aplicación y comprensión, Buenos Aires: La Plata, Edulp, 2007, p. 56 y ss. Si bien la percepción de situaciones no es la de texturas, la relación no es sólo lingüística pues el tacto es el sentido por el que percibimos el placer y el dolor que es objeto de moralidad. El lenguaje indica una relación particular de este sentido con la moralidad que no está presente en otros, por eso no se habla de vista, olfato u oído morales. El fundamento de este uso se remonta

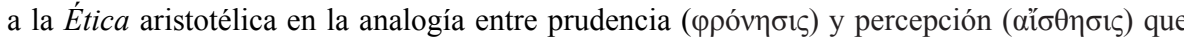
sostiene sobre la correspondencia entre la virtud de tener tacto ( $\dot{\varepsilon} \pi 1 \delta \varepsilon \dot{\xi} \xi 10 \varsigma)$ y el sentido del tacto

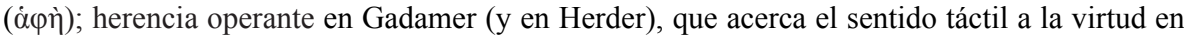
un embodiment ethics, inherente a la hermenéutica, en general, falta de carnalidad a excepción de la carne del lenguaje. 
general que permita comprenderlas y saber cómo comportarse en ellas a causa de la negatividad limitante de su carácter doloroso, propio (por la decepción de expectativas), pero sobre todo ajeno. Saber y tratar con estos límites es una cuestión de tacto como virtud y sentido. En la cercanía indesligable de

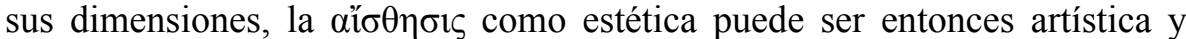
defender a la idealidad del arte contra toda restricción, pues su ilimitación requiere de la formación de este sentido virtuoso para lograr transgredir los límites de la realidad.

En la segunda frase de la definición gadameriana de tacto, al no haber mediación de un saber derivado de principios generales el tacto en tanto percepción de la singularidad de los límites en situación es inexpresado, es decir, no se comunica lingüísticamente, al igual que lo no dicho, y es inexpresable, es decir, no se puede llevar al lenguaje, al igual que lo indecible, por eso no puede aprenderse, ni imitarse, sino sólo formarse en el trato asiduo con los hombres y las cosas. ${ }^{24}$ En el conocimiento inmediato de los límites de lo singular, la sensibilidad táctil queda unida a nuestra insuperable finitud. Pertenece a los límites del lenguaje como lo no dicho y lo indecible en lo pre y sobre lingüístico. Sabe tratar con esos límites al saber hablar o callar en situaciones particulares y regula el deseo de querer decir en un tener tacto o no para la expresión. Esta virtud ético-phronética no es idéntica al tacto artístico de Helmholtz, pero para Gadamer es similar. Ambos tienen en común instituirse como una manera de conocer y de ser que es función de la formación tanto estética como histórica. Si se quiere poder confiar en el propio tacto para el trabajo espiritual-científico hay que tener o haber formado un sentido tanto de lo estético como de lo histórico (nuestro autor insiste en la terminología perceptiva): «este sentido no es una mera dotación natural es por lo que hablamos con razón de conciencia estética o histórica más que de sentido de lo uno o de lo otro. Sin embargo, tal conciencia se conduce con la inmediatez de los sentidos, esto es, sabe en cada caso distinguir y valorar con seguridad aun sin poder dar razón de ello.»> ${ }^{25}$ Opera aquí el antiguo sustrato sensible de

24 En «La verdad en las ciencias del espíritu» (1953), Gadamer explica el carácter no transmisible del tacto y su formación en el trato asiduo con las cosas: «Recuerdo que, siendo estudiante, me enzarcé en una disputa con un experto sobre una cuestión científica en la que me creía informado y que en un momento dado me dijo algo que yo desconocía. Entonces le pregunté con aspereza: ¿de dónde lo sabe usted? Su respuesta fue: cuando sea tan viejo como yo, usted también lo sabrá. Fue una buena respuesta. Pero ¿quién se atrevería a dar esa respuesta como maestro o discípulo de la ciencia natural? La mayoría de nosotros no sabe decir por qué ésta o aquella suposición de un principiante es 'imposible'. Es una cuestión de tacto adquirido mediante un trato asiduo con las cosas, pero que no se puede enseñar ni demostrar.» H.-G. Gadamer, «Wahrheit in den Geisteswissenschaften», GW 2, p. 40.

25 H.-G. Gadamer, $G W$ 1, p. 22. La inmediatez del tacto es solo aparente según Aristó- 
la reflexividad de la conciencia en la doble certeza, aparentemente inmediata, de la percepción táctil (tocante-tocado). El tacto gadameriano es ese sentido o conciencia de inmediatez necesitado de formación para agudizar su capacidad de percepción y expandir su sensibilidad ante los límites de las situaciones dolorosas propias y ajenas. Así puede limitar la universalidad metodológica de las ciencias de la naturaleza al ofrecer otro modelo estético e histórico, que

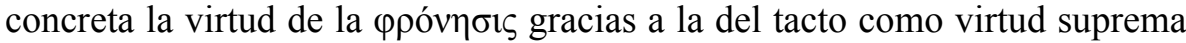
del verdadero intérprete porque frente a la finitud de la comprensión y del lenguaje, sabe orientarse entre las infinitas interpretaciones abiertas por un texto o por otro.

(III.2) La dimensión perceptiva del tacto hasta aquí entrevista en Gadamer se profundiza con el análisis de la herencia de Herder, iniciada en Verdad y Método con la referencia a la formación en vínculo con el tacto artístico, continuada en la segunda parte con sus aportes a la concepción histórica del mundo y culminada en la tercera con sus contribuciones sobre el lenguaje. En esta tercera parte, en el marco de su fundamentación de la universalidad lingüística, Gadamer explica la particularidad de su abordaje hermenéutico. Su fundamento es la unidad de lenguaje y pensamiento que Herder y Humboldt revelaron contra la teología que proponía el origen divino del lenguaje y contra el racionalismo que lo entendía como mero instrumento. Desde esa unidad la hermenéutica no se dirige al estudio de la diversidad de lenguas como hicieron ambos, sino que hace el camino inverso. Examina cómo esa unidad actúa dentro de la multiplicidad pero lo hace «partiendo de la misma concepción ${ }^{26}$ que aquellos. Atenerse a la misma concepción de partida en el caso de Herder obliga a abordar el valor que le atribuye al sentido del tacto en relación con el lenguaje, la estética y la comprensión. El carácter inexpresado de esta relación en Gadamer llama la atención no solo por ser lector de la obra herderiana desde joven y por la constante presencia de Herder en su obra mayor, sino por la importancia atribuida a este sentido/ virtud en los límites del comprender (ausencia debida quizás a la conciencia de la oscuridad histórica que envuelve al origen del lenguaje y a su búsqueda,

teles. Creemos tocar sin mediación porque la mediación de la carne nos pasa desapercibida a causa de ser un medio propio.

26 H.-G. Gadamer, $G W$ 1, p. 407. El solapamiento de ambas filosofías ha sido señalado por Irmscher, sugiriendo que la hermenéutica de Herder es una versión temprana de la de Gadamer. Cf. H. D. Irmscher, «Grundzüge der Hermeneutik Herders», en J. G. Maltusch (Hg.) Bückeburger Gespräche über Johann Gotfried Herder 1971, Bückeburger 1973. Gjesdal ha considerado que la hermenéutica herderiana es más crítica y epistemológica que ontológica. Cf. K. Gjesdal, Herder's Hermeneutics. History, Poetry, Enlightenment, Cambridge: University Press, 2017. Si bien muestran aspectos compartidos no señalan al tacto como uno de ellos. 
ya criticada como metafísica por Heidegger en su seminario de $1939^{27}$, o a un abandono demasiado apresurado de la dimensión perceptiva en pro de la ético-phronética por la ausencia de una carne que no sea del lenguaje). ${ }^{28}$

La valorización del tacto perceptivo en Herder comienza en su estética artística y se desarrolla en perspectiva de una antropología fundamental que con base en una $\alpha \ddot{\imath} \sigma \theta \eta \sigma \iota \varsigma$ ampliada abarque todos los aspectos del hombre. No sólo los procesos de conocimiento involucran razón y sentidos, sino que éstos se entrecruzan con la necesidad de formación en las distintas dimensiones humanas (estética, histórica y lingüística). ${ }^{29}$ Según Herder todos los sentidos son necesarios para el desarrollo humano. Se articulan entre sí pero según una jerarquía horizontal donde el tacto es el tronco de la sensibilidad y fundamento de todos los sentidos. ${ }^{30}$ Las razones son varias. Es el único sentido que permite la totalidad: se ubica en todo el cuerpo; hace posible percibirlo con certeza como un todo propio; ofrece la experiencia refleja de sensaciones internas y externas por estar más cerca que otros sentidos de la certeza del ser. ${ }^{31} \mathrm{Su}$

27 Cf. M. Heidegger, «Vom Wesen der Sprache. Die Metaphysik der Sprache und die Wesung des Wortes. Zu Herders Abhandlung 'Über den Ursprung der Sprache’», I. Schüßler (Hg.), Gesamtausgabe 85, 1999, XII, Vittorio Klosterman.

28 Estudios recientes, The Language of touch. Philosophical Examinations in Linguistics and Haptic Studies (MIT 2019), analizan los fundamentos hápticos (tacto y kinestésicas) del lenguaje, mostrando que la percepción táctil es inextricable a la estructura lingüística. Hay grafemas, fonemas y haptemas. Estos últimos son el fundamento sensible-material de la oralidad del lenguaje a través de los procesos táctiles del aparato fonador. La condición de existencia de lo escrito es la corporalidad sentida como propia que solo es posible gracias a la doble sensación táctil. El tacto hace audible el lenguaje en el aire haciendo posible oír lo dicho, y lo hace visible en el espacio haciendo posible ver lo escrito. Curiosamente estos estudios ignoran por completo las contribuciones hermenéuticas al giro lingüístico.

29 La valorización de Herder se desarrolla en diálogo con Locke, Condillac y Leibniz que dan prioridad al tacto como sentido fundamental para la relación con el mundo exterior, introduciendo su importancia en la teoría del conocimiento y en el desarrollo de la mente. En la estética, retoma la teoría de Baumgarten y su visión de los sentidos como una forma independiente de conocimiento que se articula con la razón.

30 La igualdad entre sentidos supone una entronización del tacto siguiendo la jerarquía vital en tanto no hay vida sensible sin tacto, contrapuesta a la clásica jerarquía cognoscitiva (vista, oído, olfato, gusto y tacto) y a la distinción entre sentidos superiores, más puros, e inferiores, sin conocimiento y ligados a la materialidad. Para Herder solo el hábito oscurece la conexión entre los sentidos y minimiza el papel del tacto, denigrándolo al más bruto. El tacto como fundamento de la sensibilidad es herencia de Aristóteles.

31 Herder afirma «un cuerpo que nunca hubiéramos conocido como cuerpo mediante el tacto, [...], sería para nosotros eternamente como un anillo de Saturno o de Júpiter, esto es, un fenómeno, una apariencia.» Formula el ejemplo que tomará Husserl: «Un oftalmita de mil ojos, sin tacto, sin mano para palpar, permanecería de por vida en la caverna de Platón y no tendría nunca el concepto de ninguna propiedad corporal singular como tal.» J. G. Herder, «Plastik», 
certeza tangible corporal excluye la duda visual del pensamiento ( ¡ $\mathrm{Me}$ toco! ¡Soy!» ${ }^{32}$ ) por eso sin tacto no hay sensibilidad, ni (auto)comprensión.

Por ser fundamento de la percepción estético-sensible, el tacto adquiere una función central en la dimensión estético-artística [Viertes Kritisches Wäldchen (1769) y Plastik (1778)]. Al ser condición básica de la percepción de cuerpos, la percepción de la belleza en las formas es inseparable del sentido del tacto. En el modelo de la escultura se hace patente. Siguiendo el ejemplo del Pigmalión de Condillac, durante la vivificación táctil de la estatua, el hombre no puede diferenciar y delimitar sus formas solo con la vista, necesita del apoyo cierto del tacto. Mientras la visión sólo se fija un instante y «resbala», el sentido del tacto hace estremecer con todos los nervios. Ofrece una paciente consideración en el trato lento y delicado con la obra de arte. Además al tocar la estatua, el hombre percibe conjuntamente sus propios límites físicos y sensaciones internas. Se siente a sí mismo (Selbstgefühl) como totalidad en la reflexividad sensible de su tacto. ${ }^{33}$ En el arte, descuidamos este sentido por confiar demasiado en la vista, pero en la búsqueda de la verdadera comprensión de una obra y de sí, y en vistas de la formación estética del hombre, la formación del tacto es fundamental: «En la vista está el sueño, en el tacto la verdad.» ${ }^{34}$ Es el sentido que guía nuestra comprensión, por eso sin él no hay estética en ninguno de los dos sentidos de la palabra (ni perceptiva ni artística).

En la dimensión lingüística [Abhandlung über den Ursprung der Sprache (1770)], la relación entre lenguaje y percepción confirma la primacía del tacto en el cruzamiento con otros sentidos, y establece la base de cualquier descripción fenomenológica del lenguaje (incluyendo el tratamiento gadameriano centrado en la percepción auditiva). ${ }^{35}$ Siguiendo a Locke, Condillac y Leibniz,

Herders Sämmtliche Werke: Plastik; Vom Erkennen und Empfinden der menschlichen Seele, Vol. 8, Weidmann, 1892, p. 7

32 J. G. Herder, «Zum Sinn des Gefühls», J. Brummack, M. Bollacher (Hg.) Schriften zu Philosophie, Literatur, Kunst und Altertum 1774-1777, Tomo 4, Frankfurt am M.: Deutscher Klassiker, 1994, p. 236.

33 Según Herder, el hombre proyecta su alma en la estatua y expande la corporeidad de la estatua y, al verla, también expande la percepción de su propio cuerpo. El alma es el lugar donde esas experiencias sensoriales (táctil y visual) se conectan en un «sensorio común». El hombre se siente a sí mismo a través de la fuerza interna de su alma. El cuerpo es el «alma al revés». Cf. Johann Gottfried Herder, «Ist die Schönheit des Körpers ein Bote von der Schönheit der Seele?», en U. Gaier u.a. (Hg.) Johann Gottfried Herder. Werke, Tomo 1, Frankfurt am M., 1985. Zeuch muestra la inexactitud de la descripción de Herder en esas conexiones entre sentidos, cuerpo y alma, y en la reflexividad sensible de la comprensión. Cf. U. Zeuch, Umkehr der Sinneshierarchie. Herder und die Aufwertung des Tastsinns seit der frühen Neuzeit, Tübingen, 2000, p. 148.

34 J. G. Herder, «Plastik», p. 9

35 Cf. A. Rodríguez Barraza, «Percepción y lenguaje: Herder o la vanguardia de la her- 
para Herder las palabras e ideas están íntimamente conectadas porque se constituyen en la interrelación de sensación y expresión. ${ }^{36}$ Todo lenguaje deriva de la sensación y es expresión de la constitución unitaria del hombre en sus distintas dimensiones, expresión de su ser un sensorio común afectado por distintos lados. En esa afección interrelacionada de sentidos, el oído es central como sentido propio del lenguaje humano porque media entre el tacto que nos arrolla con la oscuridad de sus sensaciones inmediatas y la vista que nos deslumbra con su brillantez. El sentido auditivo permite la formación del lenguaje humano porque da una sensación clara (lingüística) de lo que el hombre siente, pero es el tacto el que como fundamento de su sentir es base del lenguaje. Al penetrar intensamente en nosotros se hace inexpresable por su oscuridad, inexpresabilidad que es pedestal de la estatua lingüística, al menos por tres razones. $1^{\circ}$ ) Por ser el modo de presencia más directa y cierta de los fenómenos tangibles en el hombre y ser fundamento de todos los sentidos, sólo él otorga a las diversas sensaciones un lazo "íntimo, fuerte, indecible (unaussprechliches)» ${ }^{37}$; lazo inexpresable que abre la necesidad de expresar. Oscuridad que puede transformarse en claridad. Por eso un ser que fuera todo ojos no tendría ni cuerpo propio ni lenguaje. Por eso también el hombre considerado ya como animal, por la centralidad de su tacto, posee lenguaje ( $\sin$ tacto no habría vida sensible ni lenguaje). $2^{\circ}$ ) «Todas las sensaciones intensas de su cuerpo, y las más intensas entre las intensas, las dolorosas, todas las pasiones fuertes de su alma» ${ }^{38}$, se sienten conjuntamente por el tacto y se convierten para el oído en sonidos inarticulados propios que intentan abrirse a la expresión. El hombre, ser de tacto más agudo, sería el ser capaz de decir lo que toca su cuerpo (principalmente lo doloroso) aunque no pueda hacer siempre de su oscuro sentir táctil una palabra. ${ }^{39} 3^{\circ}$ ) El hombre es sobre todo

menéutica», Contrastes. Revista Internacional de Filosofía, vol. XIII (2008), p. 73.

36 Con Locke Herder rechaza la existencia de ideas innatas, considerando que todas las ideas son trazos de las sensaciones. Con Condillac aporta la idea de reflexión al lenguaje, y su unidad con el pensamiento. De Leibniz, asume la pluralidad de lenguas y la diversidad de ideas contenidas en ellas, entre otras. Cf. S. Sikka, «Herder on the relation between language and world», History of Philosophie Quarterly, Vol. 21, N 2, April 2004, p. 188.

37 J. G. Herder, Abhandlung über den Ursprung der Sprache, Stuttgart, Reclam, 1997, p. 30. «El oído es, entre los sentidos, el que suministra claridad y nitidez, siendo, a su vez, sentido del lenguaje ¡Qué oscuro es el tacto! Se adormece, recibe todas las sensaciones conjuntamente. Es difícil aislar en él una determinada propiedad distintiva: se hace inexpresable (unaussprechlich).» p. 32.

38 J. G. Herder, Abhandlung über den Ursprung der Sprache, p. 1.

39 Heidegger dice que por el tacto el hombre ya es desde el inicio completo y necesario, pero todavía no es sí mismo, por eso requiere de formación. Formación auditiva para adquirir el lenguaje por el que deviene más humano, pero también formación táctil, siguiendo a Aristóteles, para desarrollar su sentido más agudo. Cf. M. Heidegger, «Vom Wesen der Sprache», p. 123. 
capaz de decir los sonidos que otros cuerpos producen al tocar. Las palabras son el intento de expresar lo inexpresable porque el tacto hace sonar lo que luego, entonces, se oye. A diferencia de Condillac y Humboldt, para Herder el lenguaje se origina porque el hombre oye no la voz $\left(\varphi \omega v \eta^{\prime}\right)$ de otros o propia,

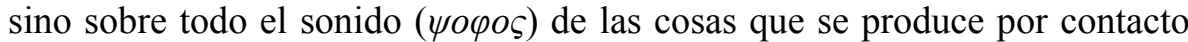
y él puede convertir en palabras por su oído. ${ }^{40}$ Las cosas suenan porque se tocan y la claridad de la palabra alcanzada por el oído humano a partir de ese sonido es, gracias al tacto del hombre, una claridad de sí: «El lenguaje como el medium de nuestro sentirse espiritual (geistigen Selbstgefühl) y de la conciencia» ${ }^{41}$ no es posible sin tacto.

\section{CONCLUSIÓN}

Si bien la herencia del tacto perceptivo de Herder no fue asumida expresamente por Gadamer, creo que su operatividad se dejar entrever en la virtud ético-phronética del tacto, central para tratar con los límites y las universalidades de la hermenéutica, y no casualmente definida en la unidad de sentido y virtud como sensibilidad ética y capacidad histórico-comunitaria de percepción de situaciones. Concentramos esa operatividad en cuatro puntos.

1) Por la impronta de totalidad y fundamento que el tacto tiene para la formación humana en Herder, la asunción de esta última por parte de Gadamer a través de su vínculo con el tacto de Helmholtz resalta la fuerza de presencia del sustrato estético-perceptivo en las dimensiones estético-artística y éticophronética. Así, por ejemplo, la función artística del tacto herderiano ofrece otra clave de comprensión para la rehabilitación estética de Gadamer que, frente a la abstracción kantiana, propone una conciencia estética e histórica que se manejan con la inmediatez del sentido (táctil), y son la base de la actitud de no-distinción estética en el trato con la obra. El tacto es el sentido que ofrece la comprensión cierta e indistinguible de lo particular de sí y de otro, sin poder dar razón de eso que da a comprender. Si bien podemos decir que como sentido perceptivo ya está desarrollado en la naturaleza, como

40 La primordialidad del tacto para hacer sonar las cosas (el agua del arroyo suena por el contacto y motiva en el hombre su palabra que es un verbo) Herder la expresa al inicio de su obra con Vocabula sunt notae rerum. Aquí resuena lo que Gadamer llamará «lenguaje de las cosas». En 1960, se preguntaba «si el lenguaje no debe ser en definitiva 'lenguaje de las cosas'-si queremos pensar realmente algo- y si no es el lenguaje de las cosas el que pone de manifiesto la correspondencia originaria entre alma y ser, de tal modo que incluso una conciencia finita pueda saber algo de ella». H.-G. Gadamer, «Die Natur der Sache und die Sprache der Dinge», GW 2, p. 69.

41 M. Heidegger, «Vom Wesen der Sprache», p. 146. Heidegger afirma que el lenguaje es «ratio - como autoconciencia» en el que y a través de lo que un hombre llega a sí mismo, es sí mismo y libre. 
capacidad histórico-comunitaria necesita de formación; formación que repite su doblez mediador: formar la virtud es también agudizar el sentido.

2) El carácter inexpresado e inexpresable del tacto gadameriano tiene su clave de lectura en la relación herderiana del sentido del tacto como fundamento oscuro e inexpresable del lenguaje que ayuda a dilucidar el trato con su universalidad y límites en la necesidad perceptiva de su descripción fenomenológica: a) El tacto es el fundamento inexpresado de la universalidad lingüística al motivar la capacidad de decir lo que se toca. Y es fundamento del deseo (ő $\rho \varepsilon \xi 1 \varsigma)$ insatisfecho de la palabra que toca al otro al querer decir lo tangible no-dicho que nunca podrá ser dicho. b) El tacto es fundamento inexpresable, límite de tales universalidades, pues su fenómeno, lo tangible, está más acá y más allá de la capacidad de decir de quien lo toca. Solo por poder tocar los límites de la singularidad de cada situación, se puede querer dejar algo sin decir. c) En la construcción del lenguaje donde el sentido «toma cuerpo» en los «sonidos lingüísticos», el juego entre la materialidad de la voz y el oído interior «es una cuestión de tacto y una cuestión de comprensión». ${ }^{42}$ Lo que se dice de la virtud se dice del sentido, pues ¿de qué plena potencialidad del lenguaje daría cuenta un ser que fuera todo oídos?

3) El tacto como sentido pertenece y toca los límites de nuestra insuperable finitud y como virtud los regula: a) la autolimitación escrita del lenguaje es materia tangible a diferencia de la oralidad; b) lo pre-lingüístico se toca, pues el tacto es inherente al límite inferior de las situaciones singulares de fuerza, violencia y amor; c) lo que está junto al lenguaje es lo que está «en contacto con» él; y d) la indecibilidad por encima del lenguaje es tocable en su inexpresabilidad, por eso no se muestra actualmente en la presencia lingüística, pero la motiva limitándola. Sin tacto no se tocan límites, ni hay finitud.

4) Si la conciencia formada estética e históricamente se conduce al modo de un tacto, la conciencia lingüística, base de la conciencia hermenéutica, debiera ser considerada también a la luz de la «inmediatez» de este sentido a pesar de estar «mediada» por el lenguaje. Es más bien gracias a esta mediación, que hace semejantes en función a la palabra y a la carne en su reversibilidad, que la conciencia lingüística se constituye como tal en la percepción táctil junto con ese medium que es su inquietante cercanía. No parece causal entonces que la encarnación del verbo, que surge de la necesidad de tocar la carne de lo divino para la salvación, sea la excepción en la historia del olvido del lenguaje. El esfuerzo carnal del oído hermenéutico por sentir(se) en el lenguaje reclama la universalidad del sentido más impuro. 
FRANCISCo Diez es Investigador adjunto del CONICET y Profesor de Antropología filosófica en la Universidad Católica Argentina y Fundamentos de Antropología en los posgrados de Enfermería de la Universidad Austral.

Lineas de investigación

Hermenéutica háptica. Un abordaje fenomenológico del lenguaje en perspeciva de la tactualidad y del cuerpo propio desde las hermenéuticas de Hans-Georg Gadamer y Paul Ricoeur

\section{Publicaciones recientes}

(2021): «Hermenéutica táctil», en Filosofia hoy. Un abordaje interdisciplinario de lo humano, Darwin Reyes-Solís (Coord.), Ed. Abya Ayala, Quito, ISBN 978-997810-579-5, 2021, pp. 9-32.

(2021): «El tacto de sí como otro. Fundamentos perceptivos de una ética encarnada en la hermenéutica de Paul Ricœur», Revista Pensando, Vol. 12, Num 26, ISSN 2178-5880, Brasil, 2021, pp. 4-20.

Correo electrónico: franciscodiezfischer@gmail.com 